\title{
Transatlantica
}

Revue d'études américaines. American Studies Journal

\section{Jacques Pothier. William Faulkner. Essayer de tout} dire.

Paris : Belin, 2003. 128 p.

\section{André Bleikasten}

\section{OpenEdition}

\section{Journals}

Édition électronique

URL : http://journals.openedition.org/transatlantica/728

DOI : $10.4000 /$ transatlantica.728

ISSN : 1765-2766

Éditeur

AFEA

Référence électronique

André Bleikasten, " Jacques Pothier. William Faulkner. Essayer de tout dire. », Transatlantica [En ligne], 1। 2003, mis en ligne le 05 avril 2006, consulté le 29 avril 2021. URL : http://journals.openedition.org/ transatlantica/728 ; DOI : https://doi.org/10.4000/transatlantica.728

Ce document a été généré automatiquement le 29 avril 2021.

\section{c) (†) $९$}

Transatlantica - Revue d'études américaines est mis à disposition selon les termes de la licence Creative Commons Attribution - Pas d'Utilisation Commerciale - Pas de Modification 4.0 International. 


\title{
Jacques Pothier. William Faulkner. Essayer de tout dire.
}

Paris : Belin, 2003. 128 p.

\author{
André Bleikasten
}

1 Jacques Pothier sait de quoi il parle. De Faulkner il a tout lu - les grands romans de Le Bruit et la fureur à Descends, Moïse, bien sûr, mais aussi les premiers poèmes et les premières proses, les textes encore tâtonnants où s'ébauchait l'oeuvre à venir (Le Faune de marbre, «La Colline ", Le Père Abraham, etc.) et les romans-palimpsestes de la fin, où la fiction faulknérienne, revenant sur ses propres traces, se relisait en se réécrivant. Et Pothier s'est également intéressé de près au Sud, à sa géographie et à son histoire, ce qui lui permet de situer avec précision les textes de Faulkner dans leurs contextes sociaux, économiques et culturels. Son ouvrage nous rappelle opportunément que cet immense romancier fut un écrivain du Mississippi et que son oeuvre s'est constamment nourrie de la riche «matière » du Sud. Mais l'approche de Pothier n'a rien de réducteur et sait éviter les écueils de l'historicisme. Ce que nous sommes invités à découvrir et à explorer, c'est d'abord l'absolue singularité d'un romancier démiurge dans la tradition de Balzac qui fut en même temps l'un des écrivains les plus inventifs et les plus novateurs du vingtième siècle. Faulkner a su créer « un cosmos bien à lui » et rien qu'à lui. Ce foisonnant univers fictionnel, Pothier s'y meut avec l'aisance et l'assurance que seule peut donner une fréquentation assidue de l'oeuvre et il se montre aussi soucieux du mouvement d'ensemble de la création faulknérienne que de son détail, aussi attentif aux constantes, à ce qui, d'un livre à l'autre, se redit et se répète, qu'aux inépuisables ressources d'une écriture romanesque qui n'a cessé de se remettre en question et de se renouveler.

Pothier aborde l'oeuvre de Faulkner dans l'ordre de sa chronologie, mais ne se contente pas de passer ses romans en revue. Le Bruit et la fureur, Absalon, Absalon!, Le Hameau et Descends, Moïse le retiennent assez longuement, Tandis que j'agonise, Sanctuaire et Lumière d'août un peu moins, Pylône et Si je t'oublie, Jérusalem n'ont droit qu'à quelques pages et sur Parabole (que Faulkner, à tort sans doute, considérait un temps comme son magnum opus) il n'y a que quelques lignes. On serait mal venu de reprocher à Pothier ses 
préférences et ses choix au nom d'une improbable «objectivité». A chacun son Faulkner. Dans ce qui, après tout, ne devait et ne pouvait être qu'une "présentation ", Pothier en dit assez pour laisser entrevoir à son lecteur l'inépuisable richesse et l'extrême complexité d'une oeuvre toute en plis et replis, et il faut lui savoir gré d'avoir accordé dans ses commentaires sur les romans et les nouvelles de Faulkner autant d'attention à leurs enjeux thématiques qu'à leur technique narrative et leurs particularités stylistiques. Le plus neuf et le plus intéressant, cependant, dans cet ouvrage, ce sont les rapprochements, inattendus parfois mais toujours éclairants, entre les textes, les réflexions sur les "scènes matricielles" (déjà relevées par Michel Gresset), la mise au jour des "réminiscences » et des "récapitulations » dans les derniers romans. Pothier fait ainsi surgir un vaste réseau intertextuel qui nous fait comprendre combien tout, dans cette oeuvre, se tient et combien, dans sa diversité, elle est une.

L'épilogue est bref, trop bref. Je l'aurais aimé plus ample, plus aigu, plus enlevé. Pothier $\mathrm{y}$ rappelle tout ce que le roman doit à Faulkner, mais il ne dit guère la force de son oeuvre, son prodigieux pouvoir de saisissement. Et je ne crois pas que Faulkner, quand il écrivait, dans le secret de sa solitude, au milieu de ses "voix", se soit soucié de « refonder un idéalisme américain humaniste ». Il avait mieux à faire.

\section{INDEX}

Thèmes : Recensions

\section{AUTEUR}

\section{ANDRÉ BLEIKASTEN}

Université Marc Bloch - Strasbourg 